\title{
A comparative finite element study of stress and deformation on three commonly used all ceramic fixed denture prosthesis under the influence of different bite forces
}

\author{
Rohit Raghavan ${ }^{1 *}$, Jency S Raj ${ }^{2}$, Shiji M Kunjappan ${ }^{3}$, Kiran Christopher ${ }^{4}$, Sapna C Kambiranda ${ }^{5}$ \\ ${ }^{1}$ Professor \& HOD, Dept. of Prosthodontics and Crown \& Bridge, Royal Dental College, Kerala, India \\ ${ }^{2}$ Post-Graduate student, Dept. of Prosthodontics and Crown \& Bridge, Royal Dental College, Kerala, India \\ ${ }^{3}$ Reader, Dept. of Orthodontics, Vinayaka Missions Sankarachariyar Dental College, Selam, India \\ ${ }^{4}$ Assistant Professor, Dept. of Mechanical Engineering, Toc H Institute of Science and Technology, Kerala, India \\ ${ }^{5}$ Senior Lecturer, Dept. of Prosthodontics, Coorg Institute of Dental Science, India \\ *Corresponding author E-mail: drrovan@gmail.com
}

\begin{abstract}
Aim: To simplify the complexity in design, modeling and analysis of Fixed Partial Dentures (FPD) and to evaluate the maximum stress and deformation developed using Finite-Element Method.

Materials and Methods: The specimen was created based on monoblock concept. The monoblock concept assumes that the total FPD unit, i.e., Abutment, pontic, connector and retainer together will act as a single unit. Monoblock castings do not differ from those made in segments and later welded as regard to the distribution of stresses. The Specimen of dimension 30 X 5 X $5 \mathrm{~mm}$ were made of the three commonly used FPD materials such as feldspathic ceramics, Lithium di silicate and Zirconia. Rectangle shape was considered with notches at 1 X 450 as a close approximation of actual FPDs. The modeling was done using Solid Works 2012, and analysis was carried out using ANSYS Mechanical APDL R14.5. The maximum stress and deformations corresponding to various masticatory loads (100 N, $500 \mathrm{~N}, 600 \mathrm{~N}, 800 \mathrm{~N} \& 1000 \mathrm{~N}$ ) were found out, and the results were compared with previous studies in FPD.

Results: The results revealed that the maximum principal stress and deformation are found at the centre of the pontic. Furthermore, it was found that for all masticatory loads, the maximum stress and deformation were encountered in Feldspathic ceramic and least for Zirconia.

Conclusion: A less complex model using the monoblock concept was developed to design and analyze FPD, so that the meshing complexities, computational time and cost can be reduced drastically. The results could well be considered as a benchmark in FPD-related studies.
\end{abstract}

Keywords: Fixed Partial Denture; Masticatory Loads; Finite Element Method; Monoblock

\section{Introduction}

There are various treatment modalities available to replace a missing posterior tooth. The conventional removable prosthesis, crown retained - Fixed Dental Prostheses (FDP's) and the recently booming implant therapy (Fradeani et al., 1997). A wide range of new materials are available nowadays: hybrid micro filled or fiber- reinforced composites (FRC), ceramics with a high content of glass particles (i.e., lithium disilicate, glass-infiltrated zirconia. Alternatively, alumina), or high-strength ceramics (densely sintered zirconia/alumina polycrystal) to be used as frameworks for subsequent veneering or to fabricate monolithic restorations (Edelhoff et al., 2001; Wolfart et al., 2006). Due to the complex shape of FPD, experimentation and modeling of the specimen is a tedious task. So a simplified model is required to analyses and design. In this study, FPD was assumed to be a monoblock of dimension $30 \times 5 \times 5 \mathrm{~mm}$ (Figure 1).

The monoblock concept assumes that the total FPD unit i.e., Abutment, pontic, connector and retainer together will act as a single unit. It helps the researcher and dental practitioner to simplify the complex FPD unit for the design and analysis.
The finite element method (FEM) is a useful tool when investigating complex systems (Chen et al., 1994; Lanza et al., 2005). Little research has been done on 'monoblock concept', and the interpretation of FEM results particularly in FPD.

Different failure theories were employed to analyses the mechanical behavior of dentures. The various theories include: Von Mises (VM), Rankine (R), Coulomb-Mohr (CM), Modified Mohr (MM) and Christensen (C). Many of the previous works had analysed the results of FE simulations from Von-Mises stresses (Kamposiora et al., 1996; Fischer et al., 2004 Eraslan et al., 2005; ; Andréa et al., 2008; Oguz et al., 2010).

Von Mises criterion is the normal criteria used by most engineers since it deals with ductile materials such as aluminum or steel and so most of the commercial FE programs use this criterion as a default output. Moreover, this criterion helps us to compare tensile strength in terms of Von Mises stress, which is a simple example of failure criteria. For brittle materials, however, it is impossible to obtain an equivalent stress from the stress tensor, regardless of the material strengths, so that it can be compared to a strength value, because the compressive strength is normally different and greater than the tensile strength (Antonia et al., 2011). In case of ductile material, the failure under uniaxial tensile stress 
occurs along plane inclined at 450 due to shearing (Rajendra, 2006). Due to this reason, The Von Mises criterion is widely used to analyses ductile materials with equal compressive and tensile strength (De et al., 1987).

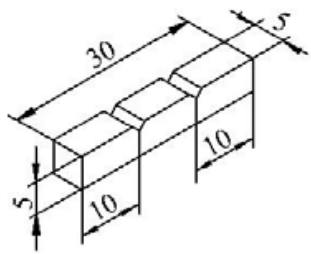

Fig. 1: Isometric View of the Specimen (All Dimensions Are in 'Mm'),

This study involves analysis of brittle materials such as feldspathic ceramics, Lithium Di silicate and Zirconia. For brittle materials, authors suggest the use of the Rankine or Maximum Normal Stress criterion to evaluate the failure in dentine, using the maximum principal stress to analyse the results (Ichim et al., 2006; Nakamura et al., 2006). The theory considers the maximum normal stress as the criterion for strength.

Using this theory, modeling was done in ANSYS, and the results were analysed to study the stress distribution and deflection of the specimen.

The main objectives of the study are (a) Simplify the complexity design, modeling and analysis of Fixed Partial Dentures (FPD) using monoblock concept, (b) Evaluate the maximum principal stress and deformation developed in the three commonly used Fixed Partial Dentures (FPD's) using Finite-Element Method (FEM), (c) Arrive at benchmark for the future FPD related studies from the obtained results.

\section{Numerical analysis}

Three commonly used denture materials such as feldspathic ceramics, Lithium disilicate and Zirconia with similar dimensions were considered. For 3D modeling CAD software (Solidworks; Dassault Systèmes) and for the analysis part ANSYS software were used.

\subsection{Modeling}

Modeling of the specimen was done with the help of wellknown parametric software Solid works. The first step in the parametric part modeling process is to create the two dimensional (2D) sketch of the specimen. The approach of creating two-dimensional sketches of the three-dimensional feature is the most effective and simplest way to construct solid models. After the two-dimensional, sketch was created the model is extruded to $5 \mathrm{~mm}$ (width) to create the 3D model as shown in Figure 1. Then the model was defined in parasolid format and then fully rendered to the ANSYS software to do the analysis part.

\subsection{Analysis}

The mechanical properties of the specimen were obtained from different authors (Fradeani et al., 1997; Edelhoff et al., 2001; Wolfart et al., 2006; Charlton et al., 2008; Li et al., 2013; Saifang et al., 2013; Natal et al., 2014; Low, 2014) and tabulated in Table 1. The analysis was done in ANSYS Mechanical APDL R14.5. The model used in this study involves several assumptions. The model is assumed to be isotropic, homogeneous and linearly elastic.

The meshing was done (Figure 1), and each mathematical model contains 28727 nodes and 6140 elements. The size of the element is 0.0005 meter, and the type of the element is SOLID e-type. The SOLID e-type is a three-dimensional finite element with three degrees of freedom at each node (translations in the nodal $\mathrm{x}, \mathrm{y}$, and $\mathrm{z}$ directions).
Table 1: Mechanical Properties of Materials Used in Tthe Analysis

\begin{tabular}{lll}
\hline Material & Young's Modulus [GPa] & Poisson's ratio \\
\hline $\begin{array}{lll}\text { Feldspathic ce- } \\
\text { ramic }\end{array}$ & $63-68$ & 0.23 \\
Lithium Disilicate & $95-100$ & 0.23 \\
Zirconia & 210 & 0.27 \\
\hline
\end{tabular}

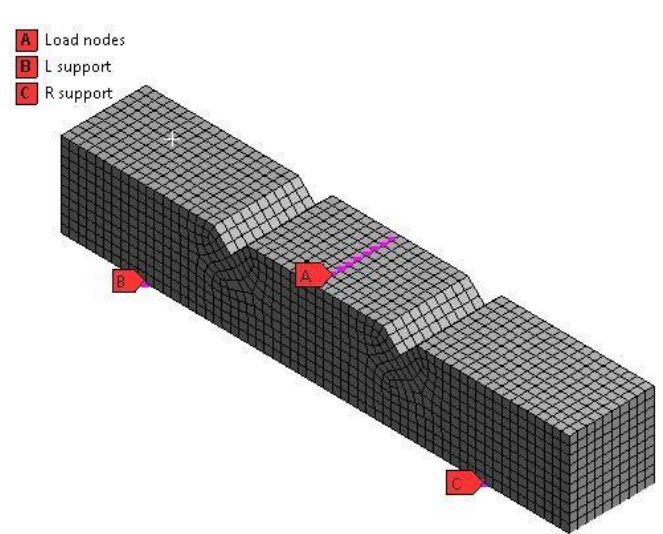

Fig. 2: Meshed Model.

The points B and C (Figure 2) are the supporting point which is at a distance of $5 \mathrm{~mm}$ from the adjacent edges. These points were fixed (all displacements are restricted) in all directions as the boundary conditions. The force loading during biting is reported to be $50-250 \mathrm{~N}$, and $500-800 \mathrm{~N}$ in para functions like bruxism (Kelly, 1995) moreover, it might reach to $1000 \mathrm{~N}$ in some conditions (Lundgren et al., 1984). In the present study $100 \mathrm{~N}, 500 \mathrm{~N}, 800 \mathrm{~N}$ and 1000N (Gerami et al., 2006; Serkan et al., 2012; Mansour et al., 2014; Lakshmi et al., 2015) were selected as the extreme case of bite forces and were applied orthogonal downwards at the centre of the model (Point A).

\section{Results}

The FEM results are presented in terms of Principal stress values. Figure 3 shows the Principal stress distribution of Lithium Disilicate when the above-mentioned bite forces are applied, and the stress values of all mentioned ceramics are summarized in Table 2. Similarly, the total deformations of the corresponding specimen under the above specified conditions are shown in Figure 4 . The total deformations of all ceramics are summarized in Table 3.

From the stress distribution (Figure 3) we can see that the stress pattern is same for all the loads (bite force), only the magnitude varies. The stress distribution is maximum at the center of the pontic, i.e. where the load is applied and minimum at both ends. In this 3D FE study, when the load is applied, it is found that the maximum principal stress is nearly same for Feldspathic ceramic and Lithium Disilicate. Slightly lesser value was obtained for Zirconia (Table 2) due to the change in the Poisson's Ratio. From the analysis, clearly the maximum stress occurs in the center of the pontic.

From Table 3 we also understand that when the static masticatory forces are applied, the total deformation is found to be maximum for Feldspathic ceramic, and the minimum deformation for the same load is found in Zirconia. This is due to the variation in the Young's Modulus, i.e., the larger the Young's modulus the lesser will be the deformation.

\section{Discussion}

The finite-element analysis is a computer-aided mathematic technique for obtaining accurate numerical solutions used to predict the response of physical systems that are subjected to external 
stress. The stress distribution in FE analysis will differ depending on the materials and properties of the material assigned to each model. FEM analysis has been extensively used to determine the stress and deformation of FPDs due to its complex structure. In the present study, the monoblock concept was introduced in FPD to simplify the complexity into the structure. Using FEM software it is possible to use a simplified model to identify the critical areas with a maximum stresses and deformation.
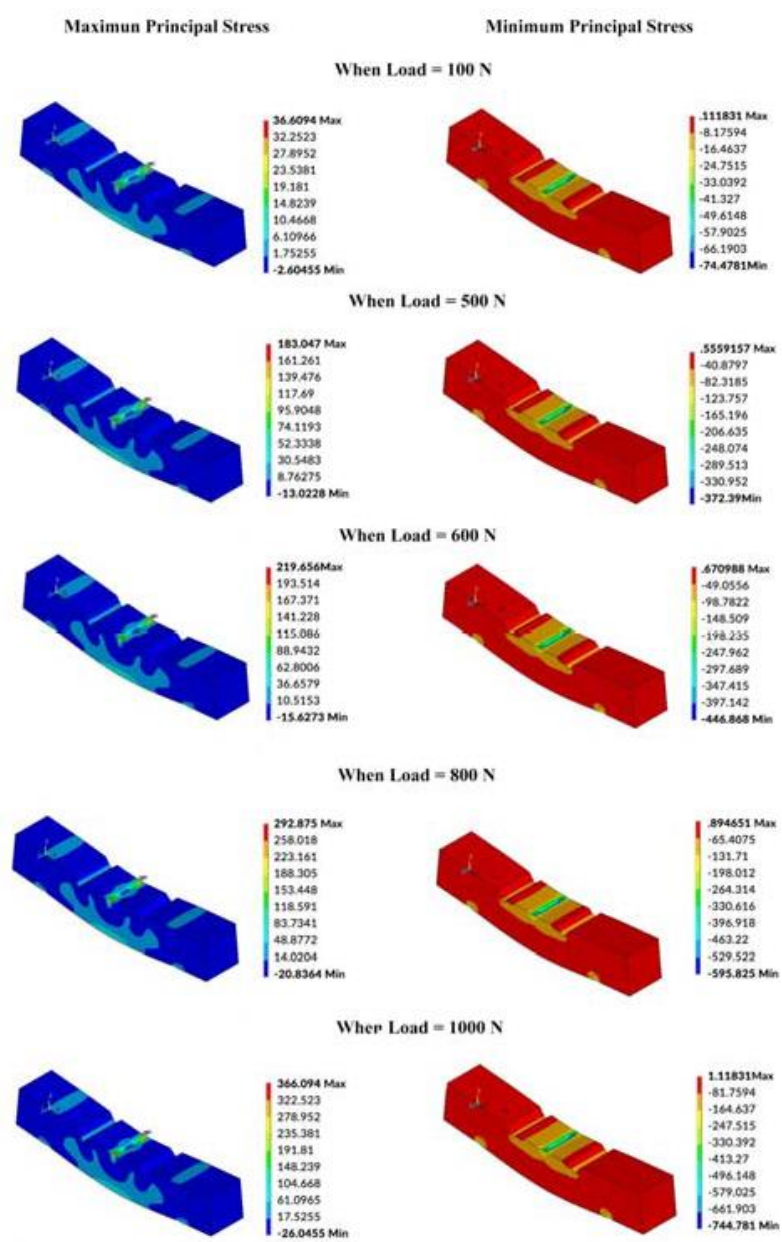

Fig. 3: Principal Stress Distribution of Lithium Disilicate Under Various Bite Forces Obtained from Finite-Element Analysis.

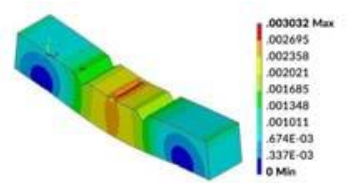

Load $=100 \mathrm{~N}$

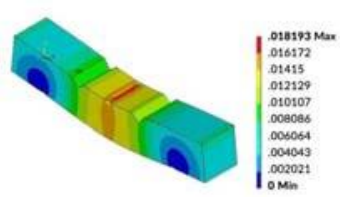

Load $=600 \mathrm{~N}$

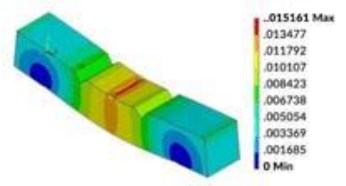

Load $=500 \mathrm{~N}$

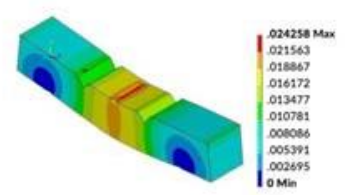

Load $=800 \mathrm{~N}$

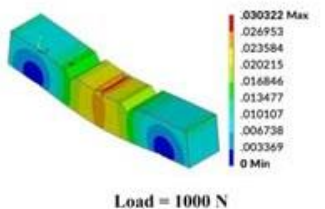

Fig. 4: Total Deformation of Lithium Disilicate Under Various Bite Forces Obtained from Finite-Element Analysis.
A maximum bending stress in the FPD is induced when the load is applied at the central part of the pontic (Low, 2014). FEM analysis presented here shows that all static masticatory forces are combined together and loaded orthogonal at the centre of the pontic. It is impossible to reproduce all masticatory forces that are induced on the tooth considering a natural course. The program assumes the model as homogeneous, linear, elastic and isotropic. Due to the above assumptions, the values obtained in this study might show a little variation from the actual values. Several studies have analyzed the stress distributions in Fixed Dental Prostheses using principal stress theory (Fischer et al., 2003; Nils et al., 2003; Eraslan et al., 2005; Paul et al., 2006; Andreia et al., 2007; Sepideh et al., 2008; Alvaro et al., 2013; Wen et al., 2011; Lakshmi et al., 2015). In one of the studies, a vertical load of $500 \mathrm{~N}$ was applied directed occlusally over a surface area of 5 $\mathrm{mm} 2$ and the results were analyzed (Lakshmi et al., 2015). In this study, the lower-right molar was fabricated with connectors of dimension $3 \mathrm{~mm} \times 3 \mathrm{~mm}$ and $4 \mathrm{~mm} \times 4 \mathrm{~mm}$. The maximum principal stress observed in this case was 135.2 $\mathrm{MPa}$ and 147.5 $\mathrm{MPa}$ for Lithium Disilicate and Zirconia respectively. Additionally, the corresponding total deformation was $0.001782 \mathrm{~mm}$ and $0.00144 \mathrm{~mm}$. The study shows that there is significant improvement in stress distribution when the dimension of connector is increased to $4 \mathrm{~mm} \times 4 \mathrm{~mm}$ in both materials.

In another study (Fischer et al., 2003), three different designs as connector areas between the abutments and the pontic was considered. In the first model, (basic model) the size of the crosssections of the connecting areas was $14 \mathrm{~mm}^{2}$. In a second model, this connecting crosspiece length was again $0.1 \mathrm{~mm}$ as in the basic model, but the size of the cross-sections of the connectors was decreased from 14 to $8.75 \mathrm{~mm} 2(2.5 \times 3.5 \mathrm{~mm})$. The connecting areas of a third model were of a size identical to that of the basic model $(3.5 \times 4.0 \mathrm{~mm})$, but the length of the connecting crosspieces was increased from 0.1 to $0.5 \mathrm{~mm}$. The bridges were loaded by $600 \mathrm{~N}$ (half-bridge model: $300 \mathrm{~N}$ ) on the occlusal surface at $90^{\circ}$ in the middle of the pontic component. The load was distributed onto three nodes of adjoining finite elements. The observations made in the study indicate that FE stress distribution is very similar for all 4 ceramics used as bridge materials. The maximum principal stress that occurred for all 4 ceramic bridges on the lower side of the area connecting the bridge abutment and the pontic component was $125 \mathrm{MPa}$ for $\mathrm{ZrO} 2$.

A unit vertical load of $100 \mathrm{~N}$ was applied at the center of the upper surface representing a 3-point-bending loading condition similar to associated standard experimental test for analyzing linear elastic stress (Nils et al., 2003). The observed maximum principal stress value in this study was $15.48 \mathrm{Mpa}$ for Zirconia. Finiteelement analyses (FEA) were also conducted using 3D images from a micro-CT scanner for modeling Zirconia dental crowns and three-unit fixed partial dentures (Alvaro et al., 2013).

In the current study a similar FE stress distribution and deformation pattern was obtained for all the three materials considered, so the stress and deformation pattern of Zirconia and Feldspathic ceramics are not included in the paper. Comparing the Table 2 and the above discussion, the result obtained i.e., Principal stress and the total deformation in our study is maximum.

Since the study is a representation of the worst-case scenario, the values obtained in the study could be considered as the bench mark in all ceramic FPDs. The model considers the maximum load that could be applied in the specimen, and the results obtained are a representation of maximum stress and deformation values that could possibly be developed in any load case. The value of maximum stress and deformation obtained in previous studies (Ichim et al., 2006) is less than that obtained in the present study and so this monoblock concept could be considered as a reference in any FPD design optimization process. 
Table 2: Comparison of Principal Stress when Different Bite Forces are applied

\begin{tabular}{|c|c|c|c|c|c|}
\hline \multicolumn{3}{|c|}{$\begin{array}{l}\text { Material } \\
\text { Bite Force }\end{array}$} & \multirow{2}{*}{$\begin{array}{l}\text { Feldspathic Ce- } \\
\text { ramic } \\
36.265\end{array}$} & \multirow{2}{*}{$\begin{array}{l}\text { Lithium Disil- } \\
\text { icate } \\
36.6094\end{array}$} & \multirow{2}{*}{$\begin{array}{c}\text { Zirconia } \\
33.5398\end{array}$} \\
\hline \multirow[b]{2}{*}{$100 \mathrm{~N}$} & Principal & Max & & & \\
\hline & $\begin{array}{l}\text { Stress } \\
{[\mathrm{Mpa}]}\end{array}$ & Min & 0.708373 & 0.111831 & 0.074812 \\
\hline \multirow[b]{2}{*}{$500 \mathrm{~N}$} & Principal & Max & 181.325 & 183.047 & 167.699 \\
\hline & $\begin{array}{l}\text { Stress } \\
{[\mathrm{Mpa}]}\end{array}$ & Min & 0.391863 & 0.559157 & 0.374059 \\
\hline \multirow[b]{2}{*}{$600 \mathrm{~N}$} & Principal & Max & 217.59 & 219.656 & 201.239 \\
\hline & $\begin{array}{l}\text { Stress } \\
{[\mathrm{Mpa}]}\end{array}$ & Min & 0.470236 & 0.670988 & 0.448571 \\
\hline \multirow[b]{2}{*}{$800 \mathrm{~N}$} & Principal & Max & 290.12 & 292.875 & 268.319 \\
\hline & $\begin{array}{l}\text { Stress } \\
{[\mathrm{Mpa}]}\end{array}$ & Min & 0.62698 & 0.894651 & 0.598494 \\
\hline \multirow{2}{*}{$1000 \mathrm{~N}$} & Principal & Max & 362.65 & 366.094 & 335.398 \\
\hline & $\begin{array}{l}\text { Stress } \\
{[\mathrm{Mpa}]}\end{array}$ & Min & 0.783726 & 1.11831 & 0.748118 \\
\hline
\end{tabular}

Table 3: Comparison of Total Deformation when Different Bite Forces are applied

\begin{tabular}{|c|c|c|c|}
\hline $\begin{array}{l}\text { Material } \\
\text { Bite Force }\end{array}$ & $\begin{array}{l}\text { Feldspath } \\
\text { ic }\end{array}$ & $\begin{array}{l}\text { - Lithium Disili- } \\
\text { cate }\end{array}$ & Zirconia \\
\hline \multirow{2}{*}{$100 \mathrm{~N} \begin{array}{l}\text { Total Defor- } \\
\text { mation }[\mathrm{Mm}]\end{array}$} & Max0.004807 & 0.003032 & 0.00142 \\
\hline & $\operatorname{Min} 0$ & 0 & 0 \\
\hline \multirow{2}{*}{$500 \mathrm{~N} \begin{array}{l}\text { Total Defor- } \\
\text { mation }[\mathrm{Mm}]\end{array}$} & Max0.024034 & 0.015161 & 0.007098 \\
\hline & $\operatorname{Min} 0$ & 0 & 0 \\
\hline \multirow{2}{*}{$600 \mathrm{~N} \begin{array}{l}\text { Total Defor- } \\
\text { mation }[\mathrm{Mm}]\end{array}$} & Max0.028841 & 0.018193 & 0.008517 \\
\hline & $\operatorname{Min} 0$ & 0 & 0 \\
\hline \multirow{2}{*}{$800 \mathrm{~N} \begin{array}{l}\text { Total Defor- } \\
\text { mation }[\mathrm{Mm}]\end{array}$} & Max0.038454 & 0.024258 & 0.011356 \\
\hline & $\operatorname{Min} 0$ & 0 & 0 \\
\hline \multirow{2}{*}{ 1000n $\begin{array}{l}\text { Total Defor- } \\
\text { mation }[\mathrm{Mm}]\end{array}$} & Max0.048068 & 0.030322 & 0.014195 \\
\hline & $\operatorname{Min} 0$ & 0 & 0 \\
\hline
\end{tabular}

\section{Conclusions}

The complex structure of the FPD makes it difficult for the researchers to design model and analyses the structure. In order to reduce these difficulties a new approach called 'monoblock' is introduced. This concept helps the researchers to create and analyses the FPDs easily so that the meshing complexities, computational time and cost can be reduced drastically. The results could well be considered as a benchmark in FPD-related studies. Within the limitations of the study the following conclusions can be drawn:

- A less complex model was developed to design and analyse FPD.

- Using the monoblock concept, the maximum possible values of stress and deformation was found and these values could be considered as a benchmark in future FPD related studies.

- When the load configuration is changed there is a significant change in stress and deformation values.

- The maximum stress and deformation are found at the center of the pontic region.

- The study also reinforces the fact that zirconium and

- Lithium Disilicate are the best suitable materials that could be used in FPD.

\section{Conflict of interests}

The authors declare that there are no conflict of interests regarding the publication of this paper.

\section{References}

[1] Fradeani Mauro, Aquilano Augusto, Bassein Leona (1997) Longitudinal Study of Pressed Glass-Ceramic Inlays for Four and a Half Years. Journal of Prosthetic Dentistry, 78 (4) 346-353. https://doi.org/10.1016/S0022-3913(97)70041-6.
[2] Edelhoff D, Spiekermann H, Yildirim M (2001) Metal-Free InlayRetained Fixed Partial Dentures. Quintessence International, 32(4), 269-281.

[3] Wolfart Stefan, Kern M (2006) A New Design For All-Ceramic Inlayretained Fixed Partial Dentures: A Report of 2 Cases. Quitessence International, 37 (1), 27-33.

[4] Chen J, Xu L (1994) A Finite Element Analysis of the Human Temporomandibular Joint. Journal of Biomedical Engineering, 116 (4), 401-407. https://doi.org/10.1115/1.2895790.

[5] Lanza A, Aversa R, Rengo S, Apicella D and Apicella A (2005) 3D FEA of Cemented Steel, Glass and Carbon Posts in a Maxillary Incisor. Dental Materials, 21 (8), 709-715. https://doi.org/10.1016/i.dental.2004.09.010.

[6] Oguz Eraslan, Ozgur Inan, Asli Secilmis (2010) The Effect of Framework Design on Stress Distribution in Implant-Supported FPDs: A 3-D FEM Study. European Journal of Dentistry, 4, 374382.

[7] Andréa Barreira Motta, Luiz Carlos Pereira, Andréia R C C da Cunha, Fernando Pereira Duda (2008) The Influence of the Loading Mode on the Stress Distribution on the Connector Region of Metalceramic and All- ceramic Fixed Partial Denture. Artificial Organs, 32 (4), 283-291. https://doi.org/10.1111/j.1525-1594.2008.00544.x.

[8] Kamposiora P, Papavasiliou G, Bayne SC, Felton DA (1996) Stress Concentration in All-Ceramic Posterior Fixed Partial Dentures. Quintessence International, 27, 701-706.

[9] Eraslan, M Sevimay, A Usumez, G Eskitascioglu (2005) Effects of Cantilever Design and Material on Stress Distribution in Fixed Partial Dentures - A Finite Element Analysis. Journal of Oral Rehabilitation, 32, 273-278. $\quad$ https://doi.org/10.1111/j.13652842.2004.01429.x.

[10] H Fischer, M Weber, M Eck, A Erdrich, R Marx (2004) Finite Element and Experimental Analyses of Polymer-Based Dental Bridges Reinforced by Ceramic Bars. Journal of Biomechanics, 37, 289294. https://doi.org/10.1016/j.jbiomech.2003.08.013.

[11] Antonio Pérez-González, José L Iserte-Vilar, Carmen GonzálezLluch (2011) Interpreting Finite Element Results for Brittle Materials in Endodontic Restorations. BioMedical Engineering On-line.

[12] Rajendra Karwa (2006) A Textbook of Machine Design. Laxmi Publications, 72-73.

[13] De Groot R, Peters MC, De Haan YM, Dop GJ, Plasschaert AJ (1987) Failure Stress Criteria for Composite Resin. Journal of Dental Research, $66 \quad$ (12), 1748-1752. https://doi.org/10.1177/00220345870660121001.

[14] Ichim I, Kuzmanovic DV, Love RM (2006) A Finite Element Analysis of Ferrule Design on Restoration Resistance and Distribution of Stress within a Root. International Endodontic Journal, 39 (6), 443-452. https://doi.org/10.1111/j.1365-2591.2006.01085.x.

[15] Nakamura T, Ohyama T, Waki T, Kinuta S, Wakabayashi K, Mutobe Y, Takano N, Yatani H (2006) Stress Analysis of Endodontically Treated Anterior Teeth Restored with Different Types of Post Material. Dental Materials Journal, 25 (1), 145-150. https://doi.org/10.4012/dmj.25.145.

[16] Charlton DG, Roberts HW, Tiba A (2008) Measurement of Select Physical and Mechanical Properties of 3 Machinable Ceramic Materials. Quintessence International, 39(7), 573-579.

[17] IM Low (2014) Advances in Ceramic Matrix Composites. Woodhead Publishing.

[18] Li Ma, Petra C Guess and Yu Zhang (2013) Load-Bearing Properties of Minimal - Invasive Monolithic Lithium Disilicate and Zirconia Occlusal Onlays: Finite Element and Theoretical Analyses. Dental Materials, 29, 742-751. https://doi.org/10.1016/j.dental.2013.04.004.

[19] Saifang Huang, Peng Cao, Chenfei Wang, Zhaohui Huang, Wei Gao (2013) Fabrication of a High-Strength Lithium Disilicate Glass-Ceramic In a Complex Glass System. Journal of Asian Ce$\begin{array}{lllll}\text { ramic } & \text { Societies, } & 1 & \text { (1), } & \text { 46- }\end{array}$ https://doi.org/10.1016/j.jascer.2013.02.007.

[20] RM Natal Jorge, JC Reis Campos, Mário AP Vaz, Sónia M Santos, João Manuel R S (2014) Biodental Engineering III. CRC Press, Taylor \& Francis Group, London, 99.

[21] Kelly JR (1995) Perspectives on Strength. Dental Materials, 2 (2), 103-110. https://doi.org/10.1016/0109-5641(95)80043-3.

[22] Lundgren D, Laurell L (1984) Occlusal Forces in Prosthetically Restored Dentitions: A Methodological Study. Journal of Oral Rehabilitation, $11, \quad 29-37$. https://doi.org/10.1111/j.13652842.1984.tb00549.x.

[23] Serkan Saridag, Atilla Gokhan Ozyesill, Gurel Pekkan (2012) Fracture Strength and Bending of All Ceramic and Fiber-Reinforced Composites In Inlay-Retained Fixed Partial Dentures. Journal of 
$\begin{array}{llll}\text { Dental Sciences, } & 7, & 159- & 164\end{array}$

https://doi.org/10.1016/j.jds.2012.03.013.

[24] Mansour Rismanchian, Soufia Shafiei, Amin Davoudi (2014) Flexural Strengths of Implant-Supported Zirconia Based Bridges in Posterior Regions. The Journal of Advanced Prosthodontics, 6(5), 346350. https://doi.org/10.4047/jap.2014.6.5.346.

[25] F Gerami- Panah, S Mir M Rezaee, L Sedighpour, F Fahimi and H Ghodrati (2006) Effect of Taper on Stress Distribution of All Ceramic Fixed Partial Dentures: A 3D- FEA Study. Journal of Dentistry, Tehran University of Medical Science, 2 (3), 109-114.

[26] RD Lakshmi, A Abraham, V Sekar, A Hariharan (2015) Influence of Connector Dimensions on the Stress Distribution of Monolithic Zirconia and Lithium-Disilicate Inlay Retained Fixed Dental Prostheses: A 3D Finite Element Analysis. Tanta Dental Journal, 12, 19. https://doi.org/10.1016/j.tdj.2015.01.001.

[27] H Fischer, M Weber, R Marx (2003) Lifetime Prediction of Allceramic Bridges by Computational Methods. Journal of Dental Re$\begin{array}{llll}\text { search, } & 82 & \text { (3), } & 238-242\end{array}$ https://doi.org/10.1177/154405910308200317.

[28] Nils Goetzen, Gerd Natt, Michael M Morlock, Joachim Tinschert (2003) Numerical Stress and Reliability Analysis of All-Ceramic Fixed-Partial Dentures. Summer Bioengineering Conference, June 25-29, Sonesta Beach Resort in Key Biscayne, Florida.

[29] Alvaro Della Bona, Marcia Borba, Paula Benetti, Yuanyuan Duan and Jason A Griggs (2013) Three-Dimensional Finite Element Modelling of All-Ceramic Restorations Based on Micro-CT. Journal of Dentistry, 41, $412 \quad-419$ https://doi.org/10.1016/j.jdent.2013.02.014.

[30] Paul H DeHoff, Kenneth J Anusavice, Nils Gotzen (2006) Viscoelastic Finite Element Analysis of an All-Ceramic Fixed Partial Denture. Journal of Biomechanics, 39, 40-48. https://doi.org/10.1016/j.jbiomech.2004.11.007.

[31] Eraslan O, Sevimay M, Usumez A, Eskitascioḡlu G (2005) Effects of Cantilever Design and Material on Stress Distribution In Fixed Partial Dentures - A Finite Element Analysis. Journal of Oral Rehabilitation, 32(4), 273-278. https://doi.org/10.1111/j.13652842.2004.01429.x.

[32] Wen Kou, Decong Li, Jiyan Qiao, Li Chen, Yansheng Ding, Goran Sjogren (2011) A 3D numerical simulation of stress distribution and fracture process in a zirconia-based FPD framework. International Journal of Biomedical Materials Research, 96 (2), 376-385. https://doi.org/10.1002/jbm.b.31782.

[33] Sepideh Mokhtarikhoee, Alireza Jannesari, Hamid Behroozi, Saeedeh Mokhtarikhoee (2008) Effect of Connector Width on Stress Distribution in All Ceramic Fixed Partial Dentures (A 3D Finite Element Study). 30th Annual International IEEE EMBS Conference, August 20-24, Vancouver, British Columbia, Canada.

[34] Andreia Barreira MOTTA, Luiz Carlos PEREIRA, Andreia RCC da CUNHA (2007) All Ceramic and Porcelain Fused to Metal Fixed Partial Dentures: A Comparative Study by 2D Finite Element Analysis. Journal of Applied Oral Science, 15 (5), 399-405. https://doi.org/10.1590/S1678-77572007000500005. 